\title{
NUMERICAL STUDY ON FLUSHING CHANNEL EVOLUTION, CASE STUDY OF DASHIDAIRA RESERVOIR, KUROBE RIVER
}

\author{
Taymaz ESMAEILI ${ }^{1}$, Tetsuya SUMI $^{2}$, Sameh A. KANTOUSH ${ }^{3}$, Yoji KUBOTA ${ }^{4}$ \\ and Stefan HAUN 5 \\ ${ }^{1}$ Member of JSCE, Ph.D. Student, DPRI, Kyoto University (Gokasho, Uji, Kyoto 611-0011, Japan) \\ ${ }^{2}$ Member of JSCE, Professor, DPRI, Kyoto University (Gokasho, Uji, Kyoto 611-0011, Japan) \\ ${ }^{3}$ Associate Professor, DPRI, Kyoto University (Gokasho, Uji, Kyoto 611-0011, Japan) \\ ${ }^{4}$ Hydro-soft Technology Institute Co., Ltd. (Nakanoshima, Osaka 530-6126, Japan) \\ ${ }^{5}$ Post-Doctoral Fellow, Institute for Modelling Hydraulic and Environmental Systems, University of Stuttgart \\ (Stuttgart 70569, Germany)
}

\begin{abstract}
Due to the high sedimentation rate in reservoirs located along the Kurobe River (e.g. Dashidaira reservoir), sediment flushing with water level drawdown is employed to preserve the effective storage capacity. During a flushing operation with full drawdown, the incoming flood erodes a flushing channel into the deposited sediment. The flushing channel evolution procedure is a complex phenomenon especially in steep reservoirs owing to the dynamic interaction between the unsteady flow field and bed variations. The flushing channel formation and evolution procedure were investigated in meandering channel of Dashidaira reservoir utilizing field measurements and numerical simulations. A 3D numerical model which applies the Finite Volume Method (FVM) in combination with a wetting/drying algorithm was used together with different bed load transport formulas. Numericaloutcomes disclosed a reasonable agreement with the field measurements. In addition, a further insight in the correlation between the flushed out sediment discharge and the water discharge as well as the water level was found.
\end{abstract}

Key Words: Dashidaira reservoir, 3D numerical model, drawdown flushing.

\section{INTRODUCTION}

The loss of reservoir storage volume due to the sediment deposition reduces the dam's effective life time and also diminishes the reservoir function for flood control purpose, hydropower generation, irrigation and water supply which represents a substantial economic loss ${ }^{1,2)}$. Various measures including sediment dredging, sediment routing, bypassing, flushing, sluicing and upstream sediment trapping have been used to control the progressive sedimentation in reservoirs. Of all the mentioned measures, flushing plays a major role in reservoir storage capacity restoration since it is an efficient hydraulic technique for sediment removal ${ }^{3)}$.

Drawdown flushing involves a complete lowering of the water level by opening the low-level outlet to temporarily establish riverine flow (i.e. free flow) towards the outlet. The accelerated flow erodes a channel through the deposits and flushes out both fine and coarse sediement ${ }^{1) ~ 3)}$. However, detailed explanation of flushing channel formation and evolution in prototype reservoir delta is scarce.

In Japan, generally the sediment yield by rivers is high due to the geologically young mountains, steep slope, and flashy flow regimes as well as wide spread landslides. Consequently, incoming sediment loads to the reservoirs fed by these rivers are high (e.g. Kurobe River located in Toyama prefecture). Kurobe River originates from the mountainous area with $3000 \mathrm{~m}$ height and flows into Toyama bay in Japan Sea. The Catchment area of the river is 682 $\mathrm{km}^{2}$ and the length of the river is $85 \mathrm{~km}$. The bed slope is steep and variesbetween $1 \%$ and $20 \%$. The average rainfall and total sediment yield per year are $4000 \mathrm{~mm}$ and $1.4 \times 10^{6} \mathrm{~m}^{3} /$ year, respectively, that are bothone of the highest in Japan ${ }^{4)}$.

For optimizing the sediment management strategies 
in reservoirs where the occurring conditions changes from shallow parts to deep parts and also sandbar areas, numerical models other than 1D should be used $^{5}$. Advanced 2D numerical models have been employed for practical problems in rivers (e.g. river meandering $)^{6}$. However, 2D and quasi 3D numerical models are not able to directly simulate a complex 3D flow field including secondary currents, whereas they have strong contribution in natural sediment transportation processes ${ }^{7)}$. Thus, utilizing of 3D numerical models are essential when the velocity variation over the flow depth, i.e. helical flow, plays a major role (e.g. in channel bends). In case of sediment flushing from reservoirs, 3D numerical model had a better performance compared to $2 \mathrm{D}$ one in simulating the bed deformation notably in channel bends ${ }^{8)}$.

In the present study, a fully3D numerical model was employed and the bed evolution trend along with the surface velocity field was simulated in Dashidaira reservoir during 2012 flushing operation. The results were compared with available field measurements. Beside this, also a variation of flushed out sediment discharge, in different stages of flushing operation, was assessed quantitatively.

\section{MATERIALS AND METHODS}

\section{(1) Study case description}

Dashidaira dam with $76.7 \mathrm{~m}$ height has been constructed in 1985 by Kansai Electric Power Company across the Kurobe River. The gross and effective storage capacity of the dam reservoir is 9.01 and $1.66 \times 10^{6} \mathrm{~m}^{3}$ respectively. Sediment flushing operation has been performed since 1991 through the bottom outlets ${ }^{3,4}$. From June 2001 a coordinated sediment flushing in both Dashidaira and Unazuki reservoir, which is located $7 \mathrm{~km}$ downstream of Dashidaira dam, is conducted. This type of flushing is done every year during the first major flood event in the rainy season, to reduce the negative environmental impacts downstream of the reservoirs.

Fig. 1 illustrates the measured bed levels before flushing operation of the reservoir that was conducted in June 2012 along with the location of cross-sections (A-F) for a further quantitative assessment of bed evolution pattern. Almost $2 \mathrm{~km}$ length of the study case has been divided into three areas, namely, area I, II and III to analyze the study outcomes based on the type of the bed material exist in each area. In area I, bed material type is coarse while in area III and the latter half of area II, they change into fine type. The total volume of the eroded sediment was equal to $408,700 \mathrm{~m}^{3} \approx 409 \mathrm{KCM}$ in the study zone. In this reservoir, almost fine sediment deposited along the left bank of the wide

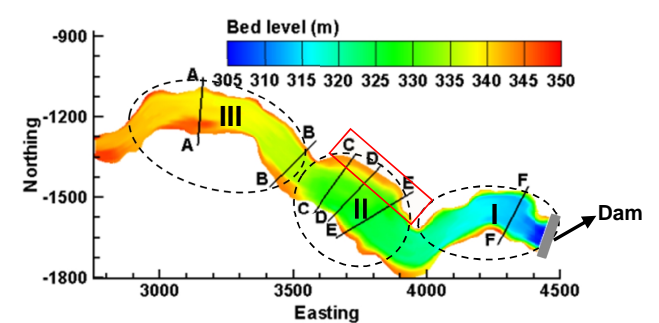

Fig. 1 Measured bed topography of Dashidaira reservoir before flushing operation in June 2012 along with the location of cross-sections A-F for bed evolution assessment. Area I, II

and III are segments with different bed material type.

middle area (i.e. area II), shown with a red line rectangle,cannot be removed effectively. Information about the flushing channel evolution in this area can beusefulfor implementing proper measures toenhance the sediment erosion and the flushing efficiency as well. Table 1 shows the average sediment size distribution, in different cross sections, before the flushing operation. Seven sediment sizes, ranged between $316 \mathrm{~mm}$ and $0.37 \mathrm{~mm}$ were considered as the representativegrainsizes.Fig. 2 shows the inflow discharge and water level changes during the 2012 flushing event in which the major sediment inflow was wash load. Preliminary drawdown was from 8 to 24 and free-flow state was from 24 to 38 hours after starting the operation.

\section{(2) Numerical model}

The numerical model solves the mass conservation equation (Eq. 1) together with the Reynolds-averaged Navier-Stokes equation (Eq. 2) to compute the water motion for turbulent flow:

$$
\begin{aligned}
& \frac{\partial U_{i}}{\partial x_{i}}=0 \\
& \frac{\partial U_{i}}{\partial t}+U_{j} \frac{\partial U_{i}}{\partial x_{j}}=\frac{1}{\rho} \frac{\partial}{\partial x_{j}}\left(-P \delta_{i j}-\rho \overline{u_{i} u_{j}}\right)
\end{aligned}
$$

Table 1. Average sediment size distribution in the reservoir entrance and specified cross-sections.

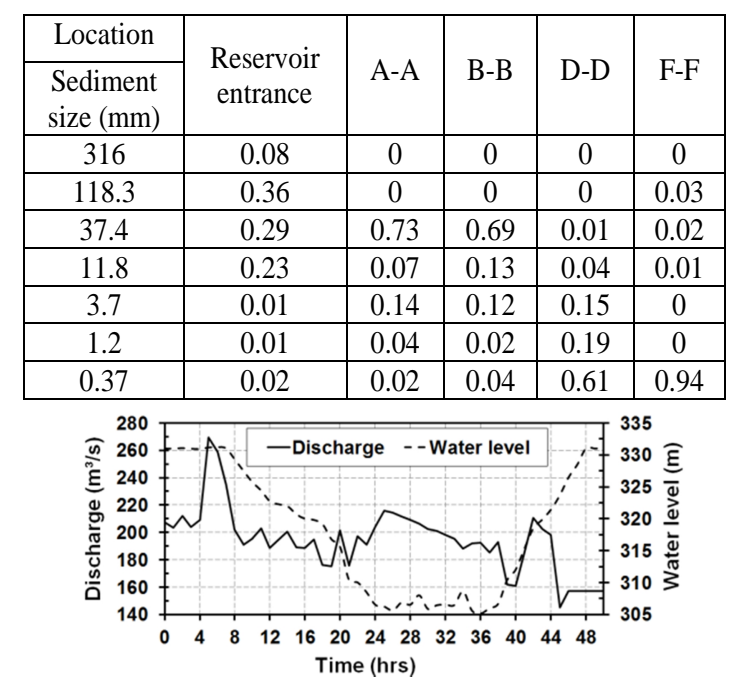

Fig. 2 Water level and discharge rates during the flushing operation in June 2012. 
in which $\mathrm{i}=1,2,3$ is the representative of three directions; where $U_{j}$ is the Reynolds-averaged velocity over time t, $x$ is the spatial geometrical scale, $\rho$ is the water density, $P$ is the Reynolds-averaged pressure, $\delta_{i}$ is the Kronecker delta and $-\rho \overline{u_{i} u_{j}}$ are the turbulent Reynolds stresses.

The finite volume approach is employed, as discretization scheme. The convective term in the Reynolds-averaged Navier-Stokes equations is solved by a second order upwind scheme. The turbulence is modeled by the standard $\mathrm{k}-\varepsilon$ model, using the constant empirical values ${ }^{9)}$. The grid is non-orthogonal, unstructured and adaptive which moves vertically with changes in the bed and free-water surface. Thus, just the water body is modeled. The grid is regenerated after each time step and an employed wetting/drying algorithm enables the model to have a varying number of grid cells (e.g. in vertical direction) with respect to the changes in water and bed level. The wetting/drying algorithm eliminates cells with a smaller water depth than a defined boundary ${ }^{10)}$.

The Dirichlet boundary condition for the water inflow (logarithmic velocity distribution) was used whereas for the water and sediment outflow a zero-gradient boundary condition was assumed. For the boundary condition at bed and walls, in where there is no water flux, wall laws were used.

Bed forms, namely dunes and ripples effect, are also taken into account through an empirical formula ${ }^{11)}$. The sediment transport computation for simulating the morphological changes is divided into suspended and bed load transport. Suspended load is calculated by solving the transient convection-diffusion equation formula and bed load can be simulated by Meyer-Peter-Müller formula (Eq. 3) (that is called MPM hereafter) or alternatively by Van Rijn formula $^{12)}$ (Eq. 4). MPM formula is more appropriate for steep rivers which mainly transport the coarse sediment close to the bed. Recently, application of Van Rijn's formula also showed a satisfactory performance in simulation of flushing operation in specific segments of some cases ${ }^{13)}$.

$$
q_{b, i}=\frac{1}{g}\left[\frac{\rho_{w} g r I-0.047 g\left(\rho_{s}-\rho_{w}\right) d_{50}}{0.25 \rho_{w}^{\frac{1}{3}}\left(\frac{\rho_{s}-\rho_{w}}{\rho_{s}}\right)^{\frac{2}{3}}}\right]
$$

where $q_{b, i}$ is sediment transportation rate for the $i$ th fraction of bed load per unit width, $\mathrm{g}$ is the gravity acceleration, $\rho_{s}$ is the density of sediment, $\rho_{w}$ is the density of the water, $d_{50}$ is the characteristic sediment size, $r$ is the hydraulic radius and $I$ is the slope of the energy line.

$$
\frac{q_{b, i}}{d_{i}^{1.5} \sqrt{\frac{\left(\rho_{s}-\rho_{w}\right) g}{\rho_{w}}}}=0.053 \frac{\left[\frac{\tau-\tau_{c, i}}{\tau_{c, i}}\right]^{1.5}}{d_{i}^{0.3}\left[\left(\frac{\left(\rho_{s}-\rho_{w}\right) g}{\rho_{w} v^{2}}\right)\right]^{0.1}}
$$

where $d_{i}$ is the diameter of the $i$ th fraction, $\tau$ is the shear stress, $\tau_{c, i}$ is the critical shear stress for $d_{i}$ which was calculated from the Shield's curve, and $v$ is the kinematic viscosity. The thickness of the upper active layer that can be eroded during a single time step as well as the lower inactive layer thickness that supplies the sufficient sediment for the active layer is introduced to the model.

Model accounted for side slope effect utilizing a reduction function of critical shear stress for incipient motion (i.e. Brooks formula) together with a sand slide algorithm ${ }^{14)}$. Sand slide algorithm will correct the bed slope when it exceeds the angle of repose of the bed material. If there is no cohesion influence, sediment particles can move independently from each other on the side slopes and bank erosion can be modeled appropriately.

\section{RESULTS AND DISCUSSIONS}

\section{(1) Model calibration}

The computational grid was made based on the measured bed levels before the flushing presented in Fig. 1. The mesh cell size in streamwise and transversal direction was $10-20 \mathrm{~m}$ and $5-10 \mathrm{~m}$ respectively. The bed material density assumed to be $2650 \mathrm{~kg} / \mathrm{m}^{3}$. The water levels and inflow discharge fluctuations, employed as the hydrodynamic boundary conditions in the simulations, are shown in Fig. 2. In addition, non-uniform bed material size distribution within the reservoir was also introduced to the model utilizing the seven representative sediment sizes. A bed material size distribution within the reservoir area was obtained based on the size interpolation of the available bed material samples. Since the wash load basically assumed to be transported without deposition in the reservoir, its effect on the bed evolution was neglected in computations.

To disclose the effect trend of parameters that are mainly empirical (e.g. active layer thickness, water content of the bed material as well as the critical angle of repose for the sand slide algorithm), first, a reference case was established with assuming the general values for the mentioned parameters. Then, assumed values have been changed and the total Volume of Flushed out Sediment (that is called TVFS hereafter) was computed and compared with the measured one (i.e. $409 \times 10^{3}$ ) for calibrating the model. Table 2 shows the sensitivity analysis of the 
TVFS to the major selected empirical parameters compared with the reference case.

As can be seen, the TVFS was enhanced with increasing the active layer thickness and the water content whereas it was reduced with increasing the critical angle of repose. When a larger amount of bed material can be eroded in one time step (i.e. thicker active layer), a higher volume of erosion from deposits is expected. Assuming a higher water content in the sediment depositions (e.g. 50\%), which decreases the submerged density of the bed material, leads to a higher sediment entrainment. A higher critical angle of repose keeps a steeper side bank of the flushing channel after each time step that results in a further deepening of the channel which is not an efficient approach for increasing the TVFS. In contrast, a lateral development of the flushing channel, that is favorable for increasing the TVFS, can be achieved by a lower critical angle of repose. Beside the TVFS, the final simulated bed topography pattern was compared qualitatively with the measurements to provide information about the erosion around the lower part of area III. Afterwards, the reference case was modified and validated with the updated values (e.g. active layer thickness, water content and critical angle of repose was set to $1 \mathrm{~m}, 40 \%$ and 33 degrees respectively).

\section{(2) Simulation of flushing channel evolution}

The numerically simulated bed levels after the flushing event in June 2012 were validated with the measured ones after the flushing. During the water level lowering, a distinctive flushing channel with free-flow condition was observed in the numerical model with similar characteristics as in the prototype. Fig. 3 demonstrates the computational grid adjustment at the beginning of the preliminary drawdown and also within the free-flow condition with a low water head in the reservoir. Cells with a lower water head than a specified value will be removed from the computational domain due to the employed wetting/draying algorithm.

Fig. 4 illustrates the simulated final bed topography after flushing by employing MPM and Van Rijn formula (Fig. 4(a) and 4(b) respectively) versus the measured one (Fig. 4(c)). As can be seen, application of Van Rijn's formula resulted in lower erosion in area III while the erosion was overestimated in area II. The computed TVFS was 313.14 KCM when MPM formula was used whereas it was $333.91 \mathrm{KCM}$ by utilizing Van Rijn's formula.

When MPM formula is employed, the eroded coarse material from area III may be deposited again in area $I$ in where the flow velocity would be reduced due to a larger water depth. In addition, in area I, the results of the simulation show a narrower
Table 2 Sensitivity analysis of reference case to the selected empirical parameters $\left(1 \mathrm{KCM}=1 \times 10^{3} \mathrm{~m}^{3}\right)$.

\begin{tabular}{|c|c|c|c|c|c|c|c|c|c|}
\hline \multirow{2}{*}{ Parameter } & \multicolumn{3}{|c|}{$\begin{array}{c}\text { Active layer } \\
\text { thickness }(\mathrm{m})\end{array}$} & \multicolumn{3}{c|}{$\begin{array}{c}\text { Water content of } \\
\text { the bed material }\end{array}$} & \multicolumn{3}{c|}{$\begin{array}{c}\text { Critical angle of } \\
\text { repose (degree) }\end{array}$} \\
\hline & 0.3 & 0.45 & 0.85 & 0.50 & 0.43 & 0.40 & 33 & 34 & 35 \\
\hline $\begin{array}{c}\text { TVFS } \\
\text { (KCM) }\end{array}$ & 261 & 290 & 300 & 369 & 306 & 313 & 311 & 302 & 284 \\
\hline
\end{tabular}

flushing channel compared to the observations regardless to the used bed-load sediment transport formulae type. This can be attributed to the complex flow field formed by secondary currents and reverse flow pattern in the wide bending area close to the dam. Bed forms (i.e. dunes and ripples) which are developed in this area will increase the complexity of the flow and subsequently the sediment transportation pattern. The empirical formula in the model to take into account the bed forms effect has been developed for small Froude numbers. Moreover, in this area the sediment transport capacity is reached to its highest level that would be smaller than the original value in the prototype. Thus, bed levels are different than measured ones.

Since bed material type and water head varies in different segments of the reservoir, each bed-load transport formula (i.e. MPM and Van Rijn) may

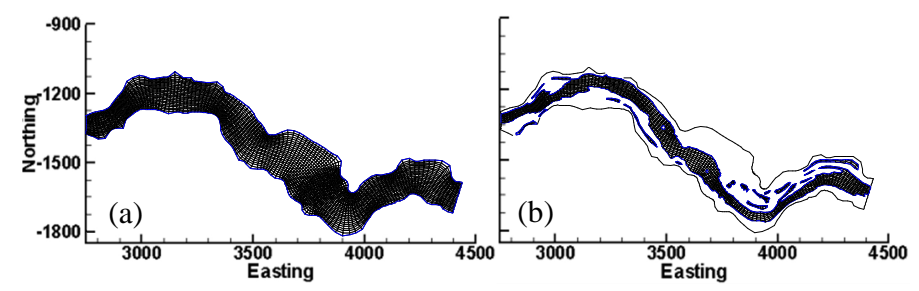

Fig. 3 Computational grid (a) at the beginning of simulation; (b) within the free-flow state ( $\mathrm{t}=32 \mathrm{hrs}$ ).

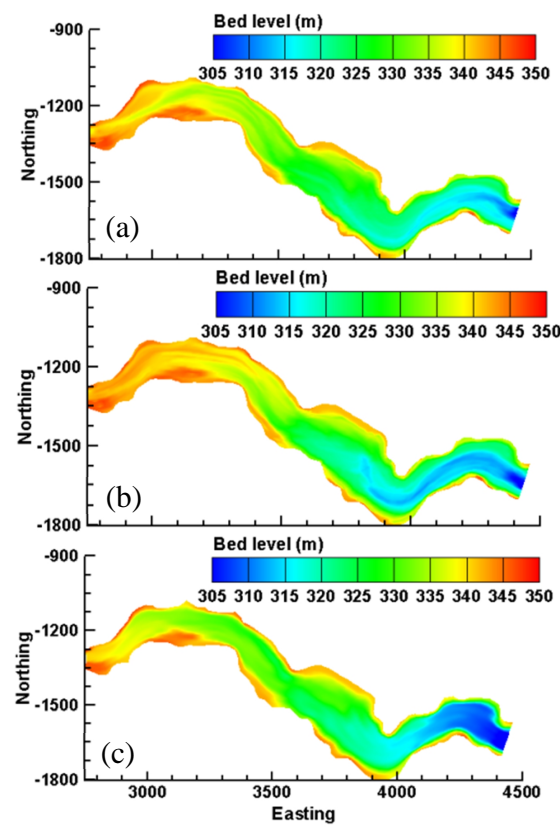

Fig. 4 Simulated bed levels after flushing employing (a) MPM formula; (b) Van Rijn formula versus (c) the measured one. 
provide a more reasonable prediction of bed evolution pattern in a specific segment. Thus, final bed levels simulated by MPM and Van Rijn's formulas have been compared with the measured one at cross-section A-A and E-E in Fig. 5. Subsequently, MPM formula was selected for further quantitative assessment of the numerical outcomes. The numerically simulated bed evolution pattern in cross-sections A-A, B-B, D-D and F-F using MPM formula is also presented in Fig. 6.

In area III, where the bed material is coarser, the sediment erosion has been underestimated and the simulated flushing channel width and depth was smaller than the measurements (Fig. 6(a) and 6(b)). Owing to the complex velocity profile and effective hydrodynamic forces on the coarse bed material, especially during the free-flow state with low water head, model could not simulate the erosion pattern properly in this area. Another reason is elimination of the cells with shallow water head (i.e. drying up), from the computational domain, along the left bank of lower part of area III in where noticeable bed degradation has been measured (Fig. 6(b)). In area , which is the wide middle segment of the reservoir, the flushing channel shape and location obtained by application of MPM formula is generally consistent with the observations. However, bed degradation has been over estimated along the right embankment in numerical outcomes (Fig. 6(c)). The flushing channel characteristics in area II have a considerable contribution in preserving the reservoir storage capacity as well as enhancing the flushing efficiency. During the free-flow flushing operation the narrow flushing channel location is deflected to the right bank region of area II and consequently there is a low chance for erosion of the large amount of deposited sediment in the left bank zone. It also should be taken into account that the sediment flushing is conducted in the rainy season in Dashidaira reservoir and bed levels measurement is not conducted right before and after the flushing event. Therefore, uncertainties would be possible in the measured bed levels. Moreover, there is also no sediment size distribution measurement with high spatial resolution along the inactive layer while it may affect the quality of the numerical model outcomes remarkably.

Fig. 7 shows the water velocity with secondary current vectors during the free-flow condition. In the flushing channel, velocities rose up to $4.5 \mathrm{~m} / \mathrm{s}$ and super critical flows emerged in several zones (Fig. 7(a) and 7(b)). 3D model also captured the characteristic of bed development in the channel bend (i.e. erosion at the outside of the bend and deposition at the inside) and reproduced the nonsymmetrical velocity profile over the width as
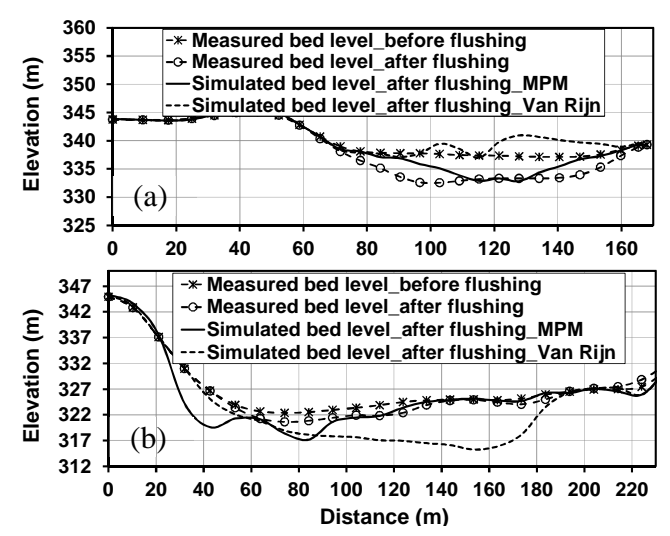

Fig. 5 Final bed level obtained by MPM and Van Rijn formula at cross section (a): A-A; (b): E-E.
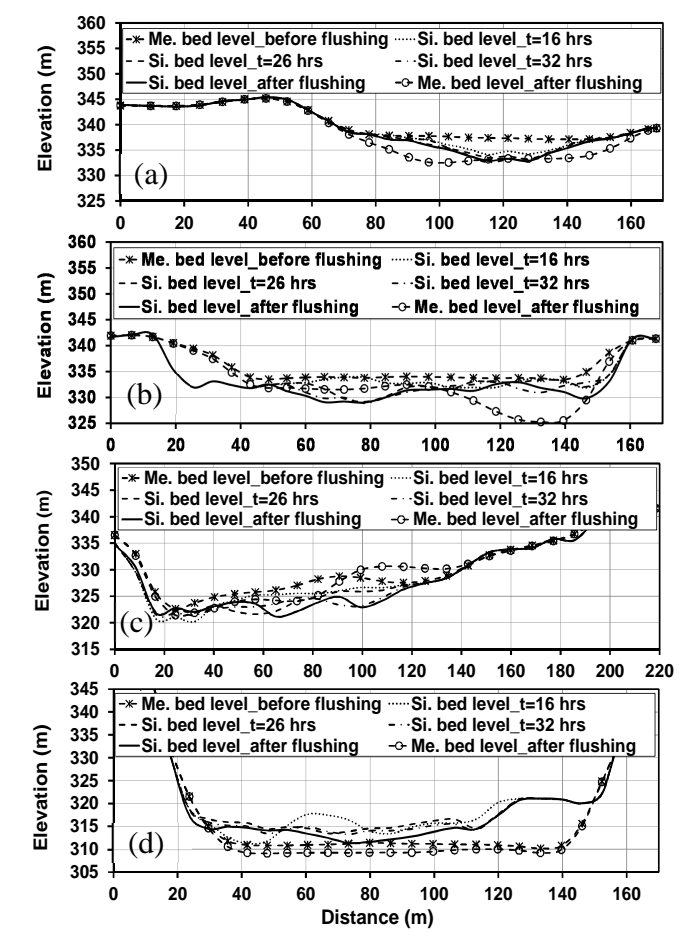

Fig. 6 Bed evolution pattern for (a) cross section A-A; (b) cross section B-B; (c) cross section D-D and (d) cross-section F-F. Me. \& Si. Are abbreviations for Measured and Simulated.

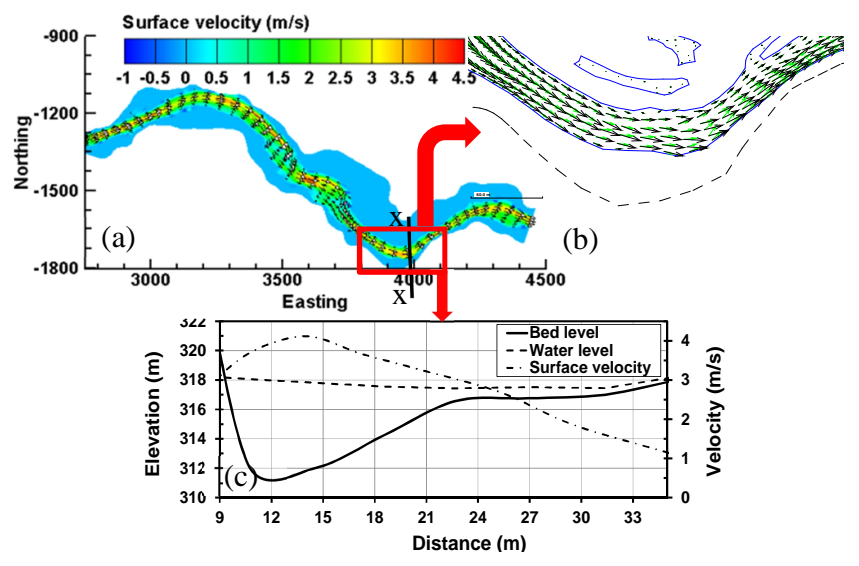

Fig. 7 (a) Simulated flow velocity field in the flushing channel during the free-flow state ( $\mathrm{t}=32 \mathrm{hrs}$ ); (b) surface velocity vector (black) and bottom velocity vector (green) showing the secondary currents development in the channel bend; (c) cross-section $\mathrm{x}-\mathrm{x}$ at the apex zone of the bend. 
well as tilting the lateral water surface in the apex of the channel bend (Fig. 7(c)).

\section{(3) Flushed out sediment discharge variation}

Fig. 8 demonstrates the computed fluxes of eroded bed material that is flushed out in one hour intervals during the flushing process mainly as the bed load. As can be clearly seen, an increase in the average flow velocity and in the fluctuation of turbulences, that is the case for the final portion of the preliminary and the free-flow stage, tends to enhance the sediment mobility and subsequently sediment entrainment.

Smaller sediment size tends to be eroded and flushed out earlier than larger sediment sizes. For instance, sand sized sediment (i.e. with diameter of $3.7 \mathrm{~mm}$ ) experiences a high concentration immediately after the flood peak at $\mathrm{t}=5 \mathrm{hrs}$. The concentrations of smaller sediment sizes are sensitive to both water level and also discharge fluctuations. On the other hand, bigger sediment sizes are more sensitive to water level changes than to discharge variations.

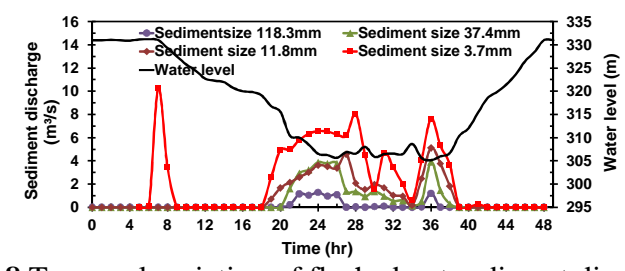

Fig. 8 Temporal variation of flushed out sediment discharge.

\section{CONCLUSION}

The following outcomes were obtained from the present study:

(a) A 3D Numerical model can properly simulate the flushing channel evolutionary pattern under the real boundary conditions (e.g. unsteady hydrodynamic conditions). Both Van Rijn and MPM bed load sediment transport formulas can represent the volume of flushed out sediment during the flushing process in a certain range. MPM formula provides a better prediction of bed level variation in the upstream area covered by the coarser materials. On the other hand, Van Rijn's formula showed a better performance in areas closer to the dam in where the bed is mainly covered with the fine material and also the reservoir is deeper. Also, the helical flow and consequent erosion and deposition pattern in channel bends could be identified by the model, which represents an advantage over 2D modeling. However, more complex bank erosion algorithms may need to be used if the bank material is influenced by cohesion or vegetation.

(b) In terms of flushed out sediment discharge during the flushing, coarser bed material is mainly flushed out at the end of the preliminary drawdown and during the free-flow state. Thus, introducing an additional water discharge and water level lowering with small fluctuations during the free flow condition may increase the erosion possibility of sediment.

\section{ACKNOWLEDGEMENT}

The authors would like to give their sincere thanks to Kansai Electric Power Co., Inc. and NEWJEC Inc. and also Mr. Shuhei Minami for providing the field data used in this study.

\section{REFERENCES}

1) Morris, G. L., and Fan, J.: Reservoir Sedimentation Handbook: Design and Management of Dams, Reservoirs and Watersheds for Sustainable Use, McGraw-Hill, New York, 1998.

2) Shen, H. W. : Flushing sediment through reservoirs, Journal of Hydraulic Research, Vol. 37, No. 6, pp. 743-757, 1999.

3) Liu, J., Minami, S., Otsuki, H., Liu, B., and Ashida, K.: Prediction of Concerted Sediment Flushing, Journal of Hydraulic Engineering, ASCE, Vol. 130, No. 11, pp. 1089-1096, 2004.

4) Minami, S., Noguchi, K., Otsuki, H., Fukuri, H., Shimahara, N., Mizuta, J., and Takeuchi, M.: Coordinated sediment flushing and effect verification of fine sediment discharge operation in Kurobe River, Proc. ICOLD conference, Japan, Kyoto, 2012.

5) Fukuoka, S., Sumi, T., and Horiuchi, S.: Sediment Management on the Arase Dam Removal Project, Proc. $12^{\text {th }}$ International Symposium on River Sedimentation, Japan, Kyoto, 2013.

6) Asahi, K., Shimizu, Y., Nelson, J., and Parker, G.: Numerical simulation of river meandering with self-evolving banks, Journal of Geophysical Research: Earth Surface, Vol. 118, pp. 1-22, 2013.

7) Fukuoka, S. and Uchida, T.: Toward Integrated Multi-Scale Simulations of Flow and Sediment Transport in Rivers, Journal of JSCE, Ser. B1 (Hydraulic Engineering), Vol. 69, No. 4, pp. II_1-II_10, 2013.

8) Haun, S. and Olsen, N. R. B.: Three-dimensional numerical modelling of the flushing process of the Kali Gandaki hydropower reservoir, Lakes \& Reservoirs: Research and Management, Vol. 17, pp. 25-33, 2012.

9) Launder, B.E. and Spalding D. B.: Lectures in Mathematical Models of Turbulence, Academic Press, London, 1972.

10) Olsen, N. R. B.: A Three-Dimensional Numerical Model For Simulation of Sediment Movements In Water Intakes With Multi-block Option, Department of Hydraulic and Environmental Engineering, The Norwegian University of Science and Technology, Trondheim, 2012.

11) Van Rijn, L. C.: Sediment Transport. Part III: Bed forms and alluvial roughness, Journal of Hydraulic Engineering, ASCE, Vol. 110, No. 12, pp. 1733-1754, 1984.

12) Van Rijn, L. C.: Sediment Transport. Part I: Bed load Transport, Journal of Hydraulic Engineering, ASCE, Vol. 110, No. 10, pp. 1431-1456, 1984.

13) Harb, G., Dorfmann, C., Schneider, J. and Badura, H.: Numerical analysis of sediment transport during a flushing event of an Alpine reservoir, Proc. $7^{\text {th }}$ River Flow conference, Switzerland, Lausanne, 2014.

14) Brooks, H. N.: Discussion of "Boundary shear stress in curved trapezoidal channels" Journal of the Hydraulic Division, ASCE, Vol. 89, No. 3, pp. 327-333, 1963.

(Received September 30, 2014) 